\title{
Association between Meningococcal Meningitis and Santa Ana Winds in Children and Adolescents from Tijuana, Mexico, a need for Vaccination.
}

Enrique Chacon-Cruz ( $\nabla$ echacon88@hotmail.com )

Hospital General de Tijuana, Mexico https://orcid.org/0000-0003-2466-4920

Erika Zoe Lopatynsky-Reyes

University of California San Diego https://orcid.org/0000-0003-4121-6521

Esbeydy Garcia

Hospital General de Tijuana, Mexico

Jesus Gilberto Montaño-Duron

Hospital General de Tijuana, Mexico

\section{Short Report}

Keywords: Meningococcal meningitis, Climate, Weather, Children, Meningococcal vaccine

Posted Date: December 16th, 2021

DOI: https://doi.org/10.21203/rs.3.rs-1174895/v1

License: (c) (1) This work is licensed under a Creative Commons Attribution 4.0 International License.

Read Full License 


\section{Abstract \\ Background}

Based on several previous studies (regional and national), Tijuana, Baja-California, Mexico (across the border from San Diego, California, USA), has shown the highest rate of Meningococcal Meningitis (MeM) in the country, however, the reason for this has not yet been known. In the "African Meningitis Belt", the Harmattan seasons are associated with MeM outbreaks. The Santa Ana winds seasons (SAWs) are hot and dry winds (similar to Harmattan seasons) that occur seasonally in southwestern California, USA, and North of Baja-California, Mexico.

\section{Objectives}

Our aim was to demonstrate, as a short communication, a potential association of SAWs with MeM in Tijuana, Baja-California, Mexico, which in turn, may partially explain the high rate of this disease in the region.

\section{Methods}

Based on own previously published data obtained from thirteen years of active surveillance of MeM, and a 65 years review showing the occurrence of SAWs, we estimated the risk ratio (RR) of total cases number by MeM vs. bacterial non-MeM (bacterial meningitis not caused by Neisseria meningitidis) during seasons with and without SAWs.

\section{Results}

We found an association of SAWs seasons with MeM, but not with bacterial non-MeM (RR $=2.06, p=$ 0.02 (95\% $\mathrm{Cl} 1.1$ to 3.8$)$, which may partially explain the high endemicity of this deadly disease in this part of the globe.

\section{Conclusion}

This study shows a new potential climatic association with MeM, and provides more information that justifies universal meningococcal vaccination in Tijuana, Mexico.

\section{Introduction}

Meningococcal meningitis (MeM) is a contagious disease transmitted from individual to individual by airborne droplets of respiratory or throat secretions. The highest burden of the disease occurs in the 
'African Meningitis Belt', a region stretching from Senegal to Ethiopia with an estimated population of 400,000 million people [1]. While Neisseria meningitidis serogroup A was the main cause for large epidemics before monovalent conjugate serogroup A meningococcal vaccine was universally administered, serogroups $\mathrm{W}, \mathrm{C}$ and $\mathrm{X}$ are also responsible for localized outbreaks [1]. Increase in incidence is typically observed during the core of the dry season, from January to March, characterized for the presence of these dry and hot winds called Harmattan. These winds blow from the northeast and carry high dust loads from January to March, before rainy seasons start [2]. These dusts mostly originate from Bode'le' (Chad) causing weekly incidence rates reaching up to 100 per 100,000 population in individual communities [2]. Even with appropriate treatment, the mortality rate fluctuates around $10 \%$, and $10-15 \%$ of survivors suffer long-term neurological sequelae $[1,2]$.

Similarly, the Santa Ana Winds seasons (SAWs) are episodic pulses of easterly, downslope, offshore flows over the coastal topography of the California Border Region: Southern California and Northern BajaCalifornia (Mexico), occurring mostly from October to April, and are associated with very dry air, often with anomalous warming at low elevations, similar to the Harmattan winds associated with MeM outbreaks in Africa [3].

Furthermore, SAWs have been associated with episodes and/or exacerbations of asthma and/or allergies [4], and maybe with Coccidiodomycosis [5].

Meningococcal universal vaccination (MUV) has never been part of the Mexican National immunization Program (NIP).

The Tijuana, Baja-California, Mexico, and San Diego, California, USA -border, is considered to be the most transited in the world.

Based on our active national surveillance studies, Tijuana has the highest incidence of MeM in Mexico, with annual attack rates varying from 2.6, 4.2 and $7.6 / 100,000$ in children $<16,5$, and 2 years of age, respectively, being Neisseria meningitidis the leading cause of all bacterial meningitis in the region [6-8]. Meningococcal serogroup $\mathrm{C}$ is predominant $(61 \%)$, followed by $\mathrm{Y}(23 \%)$.

In addition, a binational San Diego, California, USA, and Tijuana, Mexico study between 2005-2008, showed that MeM was more frequent only at the General Hospital of Tijuana when compared to the whole San Diego County in children < 16 years old (16 vs. 13 cases, respectively) [9], however, MUV at 11 years of age started in the USA since 2005, and as mentioned, is not part of the Mexican NIP.

Moreover, a serogroup C, MeM (clonal complex 11) outbreak with 19 cases occurred in 2013, and was associated with a high mortality of $36.8 \%$ [10].

In this short communication, we hypothesized that the high incidence of MeM in Tijuana may be, in part, associated with the occurrence of SAWs in the region. This association has never yet been described. 


\section{Methodology}

In one a peer-reviewed publication from our group based on 13 years of active/prospective surveillance (2005-2018), in children $>7$ days and $<16$ years of age at the General Hospital of Tijuana, we identified 51 cases of MeM (25\% lethality), and 30 bacterial non-meningococcal meningitis (NMeM) among which S. pneumoniae was predominant (42\%), followed by S. agalactiae, S. pyogenes, Enterobacteriaceae, and others [8].

A SAW episode was then defined as periods with at least 12 hours of continuous selected winds that exceed the local wind speed threshold for at least 1 hour, and from the available data between 1948-2012 (65 years summary review), 2056 SAWs episodes were detected, with an average of 32 occurrences per year, hence, a mean annual frequency of SAWs was estimated [3].

In order to only compare MeM with NMeM with/without SAWs, we did not include cases of meningococcal disease without meningitis, however, $92 \%$ of all meningococcal disease cases developed meningitis $[7,8]$.

Total number of cases of MeM and bacterial but non-MeM (NMeM) per month (from our 13 years of active/prospective surveillance data [8]) were compared with/without SAWs seasons from a 65 year review [3], and followed by Risk Ratio (RR) estimation.

The reason for comparing MeM with NMeM was basically to see whether only MeM, but not NMeM, was associated with SAWs, as with meningococcal outbreaks associated with the Harmattan condition in the African meningitis belt [2].

A $z$ test was also used to compare proportions of MeM during SAWs seasons vs. non-SAWs seasons.

\section{Results}

The RR of MeM and NMeM with/without SAWs is shown in Table 1, showing a clear statistically significant association of MeM with SAWs.

Figure 1 shows individual cases per month of MeM (red dots) and NMeM (yellow dots) obtained from our 13 years active surveillance, and, between the dotted lines, in blue bars, months with the highest mean annual frequency of SAWs, based on 65 years (1948-2012), summary review [3].

Additionally, from 51 MeM, 44 (86.27\%) occurred during SAWs seasons ( $z$ test $=7.32, p<0.0002)$.

\section{Discussion}

This is the first study that clearly associates Meningococcal Disease and a climatological condition other than the Harmattan condition. 
Both Harmattan and SAWs share similarities: 1. Both are seasonal and cyclic. 2. Are associated with dry winds, and, in the case of Harmattan seasons, lead to dust loads that allow Neisseria meningitidis to spread $[2,3]$. The latter has never been described with SAWs. However, its impact on triggering allergies and asthma has been well described [4], and there is evidence that strongly suggests that these episodes of very dry air maybe associated with higher transmission of Coccidioidomycosis, a mycotic disease that typically spreads during dry air turbulences [5].

In our study, we have shown, based on many years of prospective/active surveillance that Neisseria meningitidis is not only the leading cause of bacterial meningitis in Tijuana, Mexico [7, 8], but similarly proved, based on the same surveillance system in nine hospitals within the country, that MeM has much higher endemicity in Tijuana than other geographic regions in Mexico [6], from which an explanation of this phenomena is mandatory. Our elevated rates of MeM $(2.69 / 100,000$ in $<16$ years of age [7]) in a city of two million people may be seen not concordant with 51 cases in thirteen years, nonetheless, as we described this when we published our studies [7, 8], in the state of Baja-California, Mexico, during the time of our active surveillance, there were mainly five different health care systems: "Instituto Mexicano del Seguro Social" (IMSS), "Seguro Popular", "Instituto de Seguridad Social para Trabajadores del Estado" (ISSSTE), "Instituto de Seguridad Social para Trabajadores de Baja-California" (ISSSTECALI), and "PEMEX" [11]. The General Hospital of Tijuana was the only one attending patients belonging to the "Seguro Popular" health care system, therefore, attack rates by age groups were estimated by using that "Seguro Popular" population as a denominator, with the potential disadvantage that maybe some patients with MeM belonging to "Seguro Popular" were hospitalized in the private sector, potentially leading to under estimation. In addition, even though MeM is of mandatory report in Mexico, no other hospital than the General Hospital of Tijuana has established well active surveillance system including both clinical and laboratory trained personnel and resources. All of the latter was explained and accepted in our publications $[7,8]$.

The main limitation of our study is indeed the lack of data from other places where SAWs also occur, and this association is coming only from one hospital. In Baja-California, Mexico, the General Hospital of Tijuana, where all cases of bacterial meningitis were obtained for this study, is the only hospital that actually performs active surveillance in the State (as mentioned), hence, information from other hospitals where SAWs occur in the region is practically absent. In Southern California there are no studies of this association, moreover, since MUV is part of the NIP in the USA (started in 2005), trying to make an association of MeM with SAWs could now be very difficult to estimate. Additionally, as we mentioned in the Introduction section, we have published a binational (Tijuana, Mexico-San Diego, California) study between 2005-2008, with more MeM cases only at the General Hospital of Tijuana when compared to all the San Diego County [9].

We are aware that other factors can be associated with higher endemicity of MeM in our region, such as a potential higher nasopharyngeal carriage in the population (studies never performed to date), high rate of migration from Central and South America, many areas of people congregation, among others. 


\section{Conclusions}

This short report showed a statistically significant association of MeM during the SAWs seasons when compared to bacterial but non-MeM, strongly suggesting that this hot, dry SAWs may intervene in a higher transmission and occurrence of this potentially deadly disease. Nonetheless, our results do not prove causality, but rather a hypothesis that, along with previous data showing a higher rate of MeM in Tijuana, Baja-California, Mexico, urges serious consideration for universal vaccination against Neisseria meningitidis in this region.

\section{Declarations}

\section{Ethical approval or consent to participate:}

This study was approved during the period of active surveillance from the "Comite de Etica en Investigacion del Hospital General de Tijuana" (Ethics Committee in Research of the General Hospital of Tijuana), number CONBIOETICA02CE1001-20170526. No additional authorization was needed since this study is showing an association from two previous publications, and, coming from those same approved and published data, an association to Santa Ana winds.

\section{Consent for publication:}

Not applicable.

\section{Availability of data and materials:}

Not applicable since this study is showing a relationship between a climatic condition and an infectious disease from prior publications. Nonetheless, data from our prior publication is available (anonymously) in an Excel file.

\section{Competing interests:}

Not applicable.

\section{Funding:}

This study was $100 \%$ self-funded.

\section{Authors contributions:}

All authors need have contributed to this study based on the following:

1. Made a substantial contribution to the concept of the work; as well for data interpretation.

2. Revised the article critically for important intellectual content,

3. Approved the version to be published, 
4. Each author participated sufficiently in the work to take public responsibility for appropriate portions of the content.

\section{Acknowledgements:}

Not applicable.

\section{References}

1. Patel JC, Soeters HM, Diallo AO, et al. (2019). MenAfriNet: A network supporting case-based meningitis surveillance and vaccine evaluation in the meningitis belt in Africa. J Infect Dis; 220 (Suppl 4): S148-S154. Doi: 10.1093/infdis/jiz308.

2. Agier L, Deurobaix A, Martyini N, et al. (2013). Seasonality of meningitis in Africa and climate forcing: aerosols stand out. J R Soc Interface; 10: 1-11. Doi: 10.1098/rsif.2012.0814

3. Guzman-Morales J, Gershunov A, Theiss J, et al. (2016). Santa Ana Winds of Southern California: Their climatology, extremes, and behavior spanning six and a half decades Geophys. Res. Lett, 43: 2827-34. Doi: 10.1002/2016GL067887

4. Corbett SW. (1996). Asthma exacerbations during Santa Ana Winds in Southern California. Wild Environ Med; 7: 304-311. Doi: 10.1580/1080-6032(1996)007[0304:aedsaw]2.3.co;2

5. Tong DQ, Wang JXL, Gil TE, et al. (2017). Intensified dust storm activity and Valley Fever infection in the Southwestern United States. Geophys. Res. Lett, 44: 4304-12. Doi: 10.1002/2017GL073524

6. Chacon-Cruz E., Martinez-Longoria CA, Llausas-Magana E, et al. (2016). Neisseria meningitidis and Streptococcus pneumoniae as leading causes of pediatric bacterial meningitis in nine Mexican hospitals following three years of active surveillance. Ther. Adv. Vaccines; 4: 15-9. Doi:

$10.1177 / 2051013616650158$

7. Chacon-Cruz E, Alvelais-Palacios JA, Lopatynsky-Reyes EZ, et al. (2017). Meningococcal disease in Children: Eleven years of active surveillance in a Mexican hospital and the need for vaccination in the Tijuana region. J. Infect. Dis. Treat, 3: 1-4. Doi: 10.21767/2472-1093.100031

8. Chacon-Cruz E, Roberts C, Rivas-Landeros RM, et al. (2019). Pediatric meningitis due to Neisseria meningitidis, Streptococcus pneumoniae and Group B Streptococcus in Tijuana, Mexico: active/prospective surveillance 2005-2018. Ther. Adv. Vaccines; 6: 1-7. Doi: $10.1177 / 2049936119832274$

9. Chacon-Cruz E, Sugerman DE, Ginsberg MM, et al. (2011). Surveillance for meningococcal disease in children, US-Mexico border, 2005-2008. Emerg. Infect. Dis; 17: 543-6. Doi: 10.3201/eid1703.101254

10. Chacon-Cruz E, Espinosa De Los Monteros LE, Navarro-Alvarez S, et al. (2014). An outbreak of sergroup C (ST-11) meningococcal disease in Tijuana, Mexico. Ther. Adv. Vaccines; 2: 71-6. Doi: $10.1177 / 2051013614526592$

11. Estudio Básico de Comunidad Objetivo (2015). "Panorama sociodemográfico del municipio de Tijuana, el estado de Baja California y Nacional." http://www.cij.gob.mx/ebco2018- 


\section{Table}

TABLE 1 RISK RATIO ESTIMATION OF MENINGOCOCCAL (MEM) AND BACTERIAL-NONMENINGOCOCCAL MENINGITIS (NMEM) WITH SANTA ANA WINDS (SAWS) SEASONS

\begin{tabular}{|l|c|c|}
\hline & SAWs seasons & Non-SAWs seasons \\
\hline MeM & 44 cases & 7 cases \\
\hline NMeM & 17 cases & 13 cases \\
\hline
\end{tabular}

$\mathrm{RR}=2.06, \mathrm{p}=0.02(95 \%$ CI 1.1 to 3.8$)$

\section{Figures}

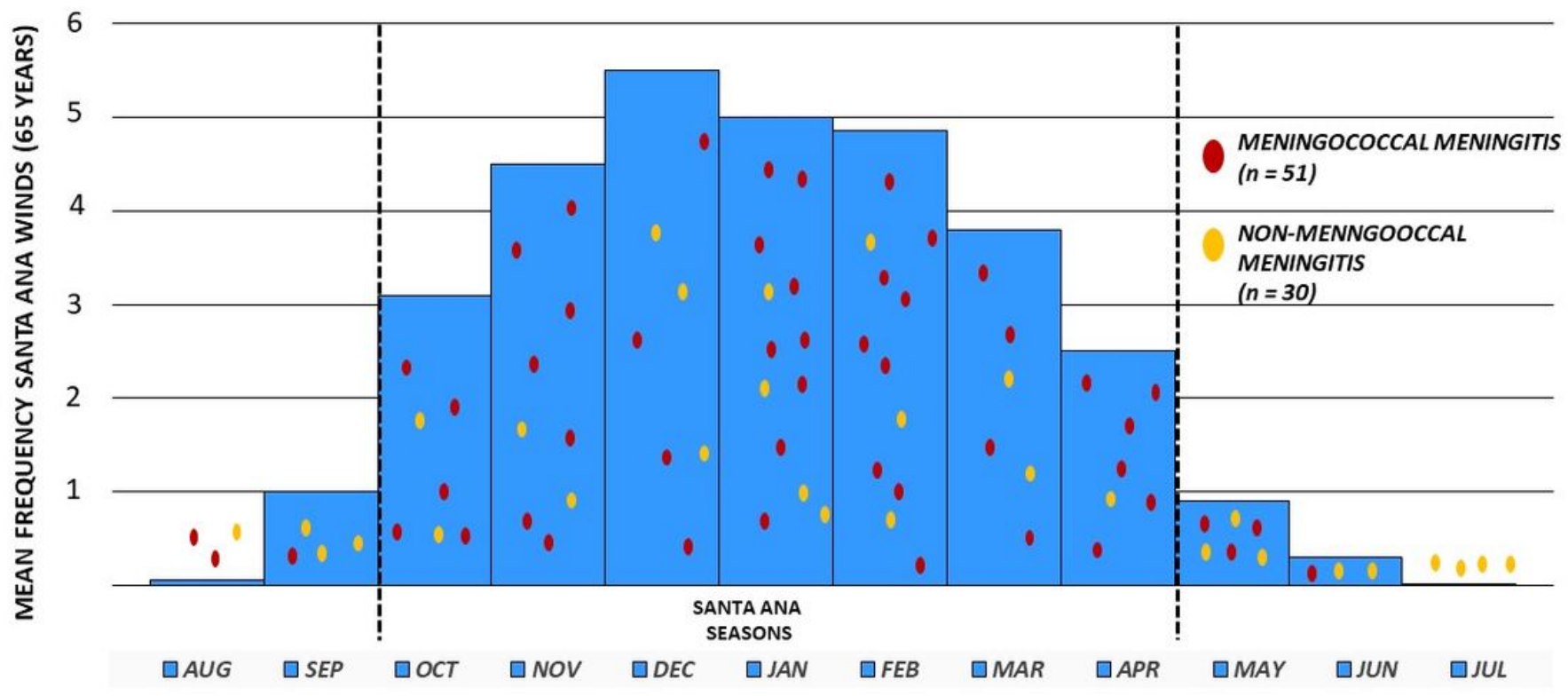

Figure 1

ASSOCIATION OF MEAN ANNUAL FREQUENCY OF SANTA ANA WINDS (1948-2012) AND MENINGOCOCCAL MENINGITIS IN TIJUANA, MEXICO, 2005 - 2018. 